Supplement of Clim. Past, 15, 449-462, 2019

https://doi.org/10.5194/cp-15-449-2019-supplement

(C) Author(s) 2019. This work is distributed under

the Creative Commons Attribution 4.0 License.

(c) (1)

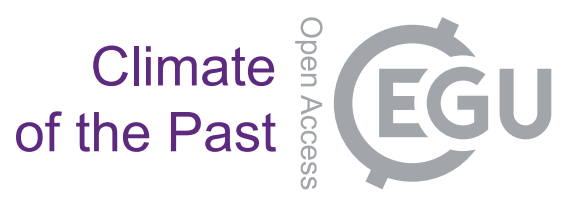

Supplement of

\title{
The response of tropical precipitation to Earth's precession: the role of energy fluxes and vertical stability
}

Chetankumar Jalihal et al.

Correspondence to: Chetankumar Jalihal (jalihal@iisc.ac.in)

The copyright of individual parts of the supplement might differ from the CC BY 4.0 License. 


\section{JJA mean}
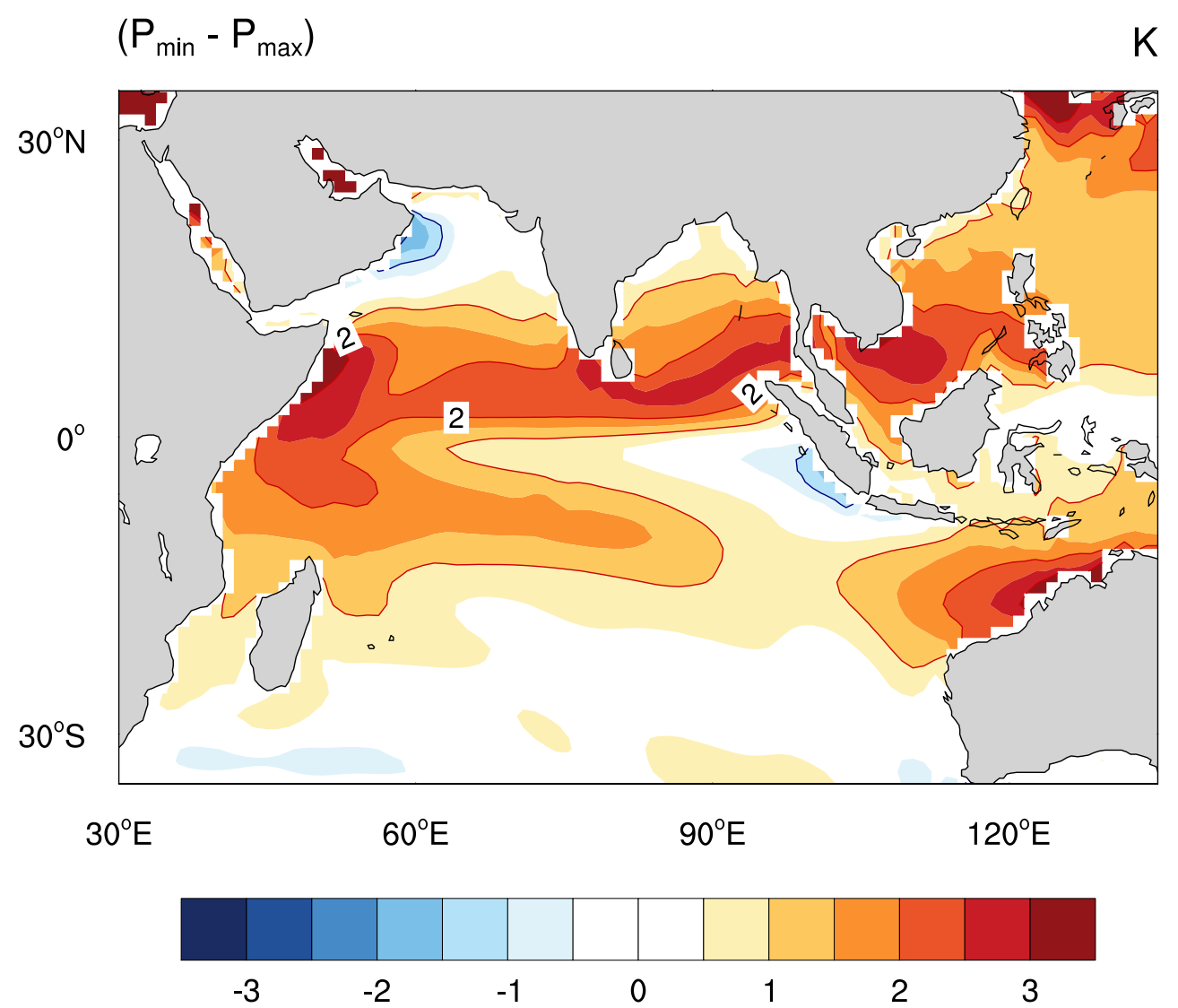

Figure S1. The difference SST between $\mathrm{P}_{\min }$ and $\mathrm{P}_{\max }$, averaged over the months JJA. It shows that most of the Indian ocean has warmed in $\mathrm{P}_{\min }$. The largest warming is at the west equatorial Indian Ocean. This is due to the northward shift of LLJ, which reduces upwelling. It also increases upwelling along the coast of Middle-east, leading to enhanced cooling there.

\section{S1 Mid-Holocene}

The results of the Mid-Holocene (MH) from the simulations of Bosmans et al. (2012) using EC-Earth are discussed here. The MH-PI response is similar to that of $\mathrm{P}_{\min }-\mathrm{P}_{\max }$. The dominant forcing in $\mathrm{MH}$ is that of precession, and obliquity plays a minor role (Fig. S2). There is a land-sea shift in the response of the tropical precipitation (Fig. S3). However, the peak response is

5 delayed by about a month with respect to $\mathrm{P}_{\min }-\mathrm{P}_{\max }$ (Fig. S3). This is on account of the forcing which also shows a shift with respect to the forcing of $\mathrm{P}_{\min }-\mathrm{P}_{\max }$ (Fig. S2a). Hence, for our analysis with MH, we consider JAS and JFM instead of JJA and DJF, respectively.

Qualitatively changes in P-E over the tropics is explained mainly by the changes in $\mathrm{Q}_{\text {div }}$ (Fig. S4). P-E has increased over most of the land regions, but over the ocean, the precipitation response is heterogeneous. Using Eq. 15 of the main article, we have attributed the causes of these changes to either $\mathrm{Q}_{\text {div }}$ or TGMS (Fig. S5). The tropical mean response is not representative of individual regions. Particularly over India and the Bay of Bengal, we find that the change in P-E is due to $\mathrm{Q}_{\text {div }}$. This is due to increased insolation over India, and due to decreased LHF over the Bay (Fig. S6). Winds in the Bay decrease due to convective heating over the Western Equatorial Indian Ocean and the Red Sea (Fig. S7), which reduces LHF over the Bay. 


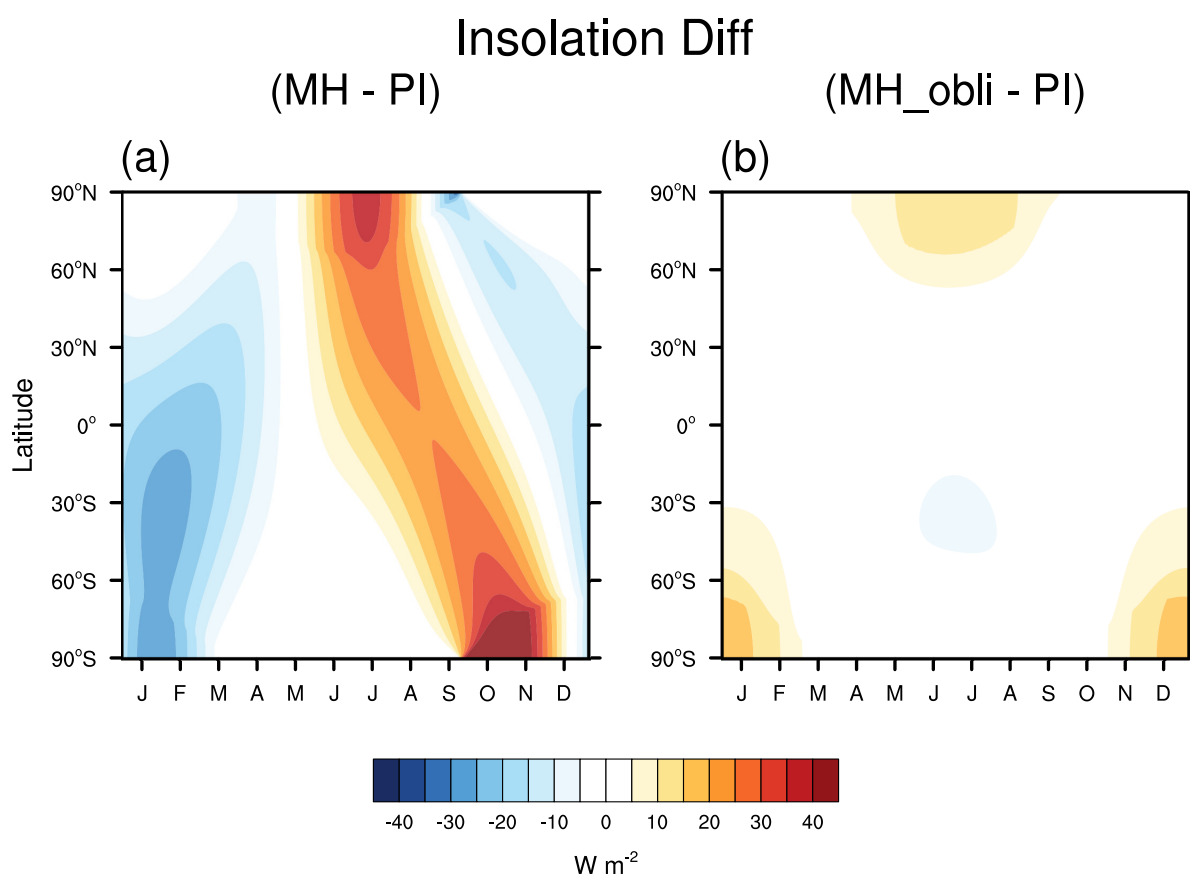

Figure S2. The difference in insolation between, a) MH and PI, b) MH (obliquity only) and PI. This figure shows that the contribution from tilt to the total insolation change is much smaller in comparison to that from precession. The peak in the forcing occurs in July, a month after that in $\mathrm{P}_{\min }-\mathrm{P}_{\max }$. 
$(\mathrm{MH}-\mathrm{PI})$

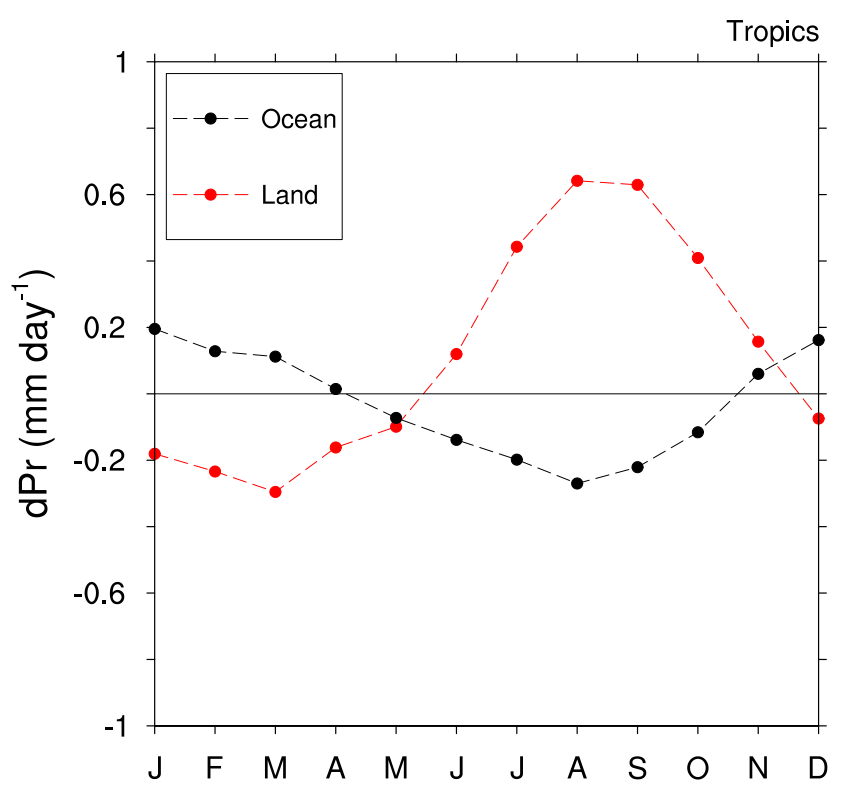

Figure S3. The difference in precipitation MH-PI for the tropical land and ocean taken separately $\left(30^{\circ} \mathrm{S}-30^{\circ} \mathrm{N}\right)$. This shows the asymmetric response of the land and oceans to the $\mathrm{MH}$ forcing.
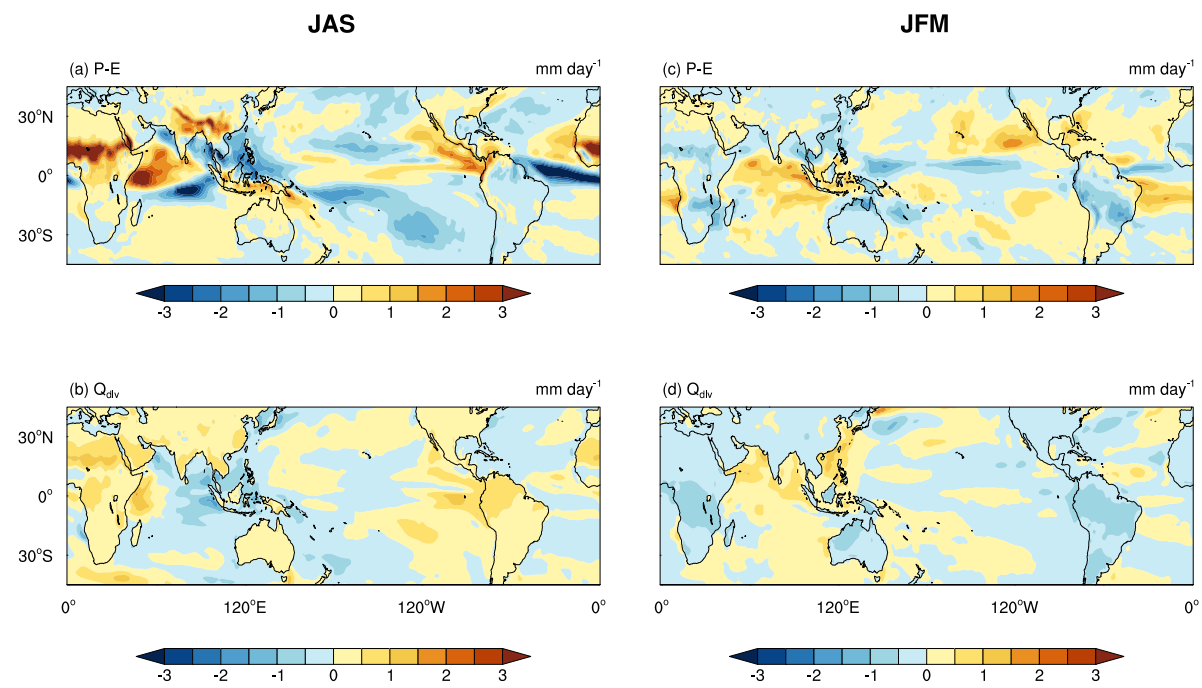

Figure S4. The difference in P-E (top panel (a) and (c)) and $\mathrm{Q}_{\text {div }}$ (bottom panel (b) and (d)). The left panel are for JAS mean and the right panel for JFM mean. This shows qualitatively that $\mathrm{Q}_{\text {div }}$ explains most of the changes in precipitation over the tropics. 

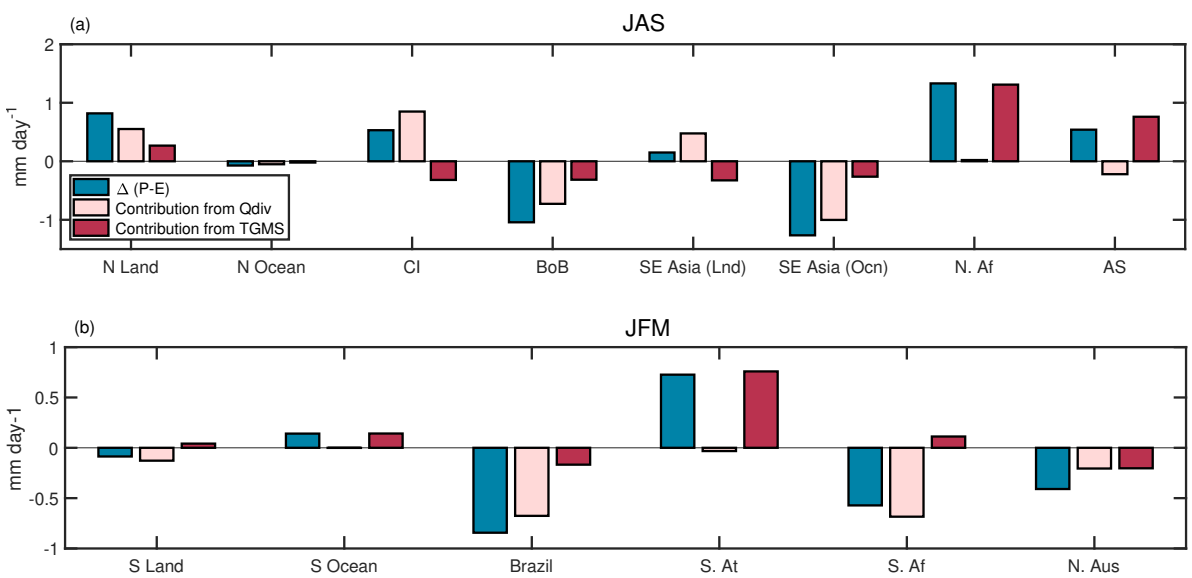

Figure S5. The contribution of $\mathrm{Q}_{\text {div }}$ and TGMS to the changes in P-E. The top panel (a) is for JAS mean and regions in the Northern Hemisphere, and the bottom panel (b) is for regions in the Southern Hemisphere and averaged over JFM. The blue stick is the change in P-E, while pink and red sticks represent the contribution from $\mathrm{Q}_{\text {div }}$ and TGMS. The abbreviations used in (a), N Land: Northern tropics (land only), N Ocean: Northern tropics (Ocean only), CI: Central India, BoB: Bay of Bengal, SE Asia (Lnd): South East Asia (land only), SE Asia (Ocn): South East Asia (Ocean only), N. Af: North Africa and AS: Arabian sea. And in (b), S Land: Southern tropics (land only), S Ocean: Southern tropics (ocean only), S. At: South Atlantic, S. Af: South Africa, N. Aus: North Australia. The co-ordinates of these regions are provided in table 2. Ocean response is heterogeneous. Hence, the tropical mean changes in P-E over ocean is very small. Over land, $\mathrm{Q}_{\text {div }}$ explains most of the changes when averaged over the whole tropics, but there are land regions (e.g. North Africa) where changes in TGMS is dominant. P-E change over $\mathrm{CI}$ and $\mathrm{BoB}$ is due to changes in $\mathrm{Q}_{\text {div }}$. 
JAS
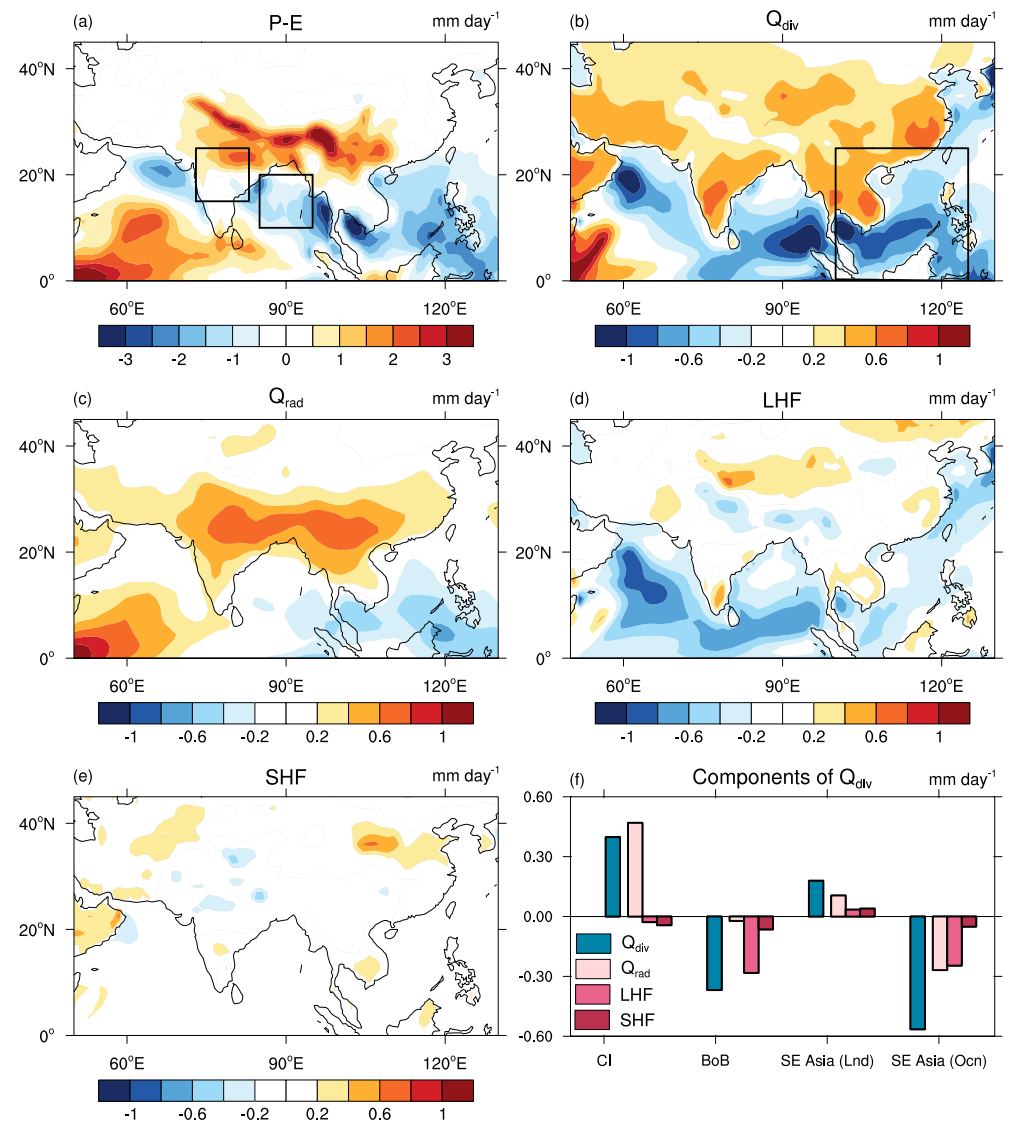

Figure S6. The JAS mean difference $\mathrm{P}_{\min }-\mathrm{P}_{\max }$, in (a) $\mathrm{P}-\mathrm{E}$, (b) $\mathrm{Q}_{\text {div }}$ (sum of fluxes at the top and bottom of the atmosphere), (c) $\mathrm{Q}_{\text {rad }}$ (Sum of all radiative fluxes at the top and bottom of the atmosphere), (d) Latent Heat Flux, (e) Sensible Heat Flux. The boxes shown in (a) and (b), are the regions chosen for this study: Central India $\left(15^{\circ} \mathrm{N}-25^{\circ} \mathrm{N} ; 73^{\circ} \mathrm{E}-83^{\circ} \mathrm{E}\right)$, Bay of Bengal $\left(10^{\circ} \mathrm{N}-20^{\circ} \mathrm{N} ; 85^{\circ} \mathrm{E}-95^{\circ} \mathrm{E}\right)$ and South East Asia $\left(0^{\circ} \mathrm{N}-25^{\circ} \mathrm{N} ; 100^{\circ} \mathrm{E}-125^{\circ} \mathrm{E}\right)$. (f) shows the decomposition of $\mathrm{Q}_{\text {div }}$ into radiative, latent and sensible heat fluxes for the two regions. The bar chart in (f) shows that the radiation terms drive changes over land whereas the changes in LHF are large over oceans. 


\section{JAS mean}

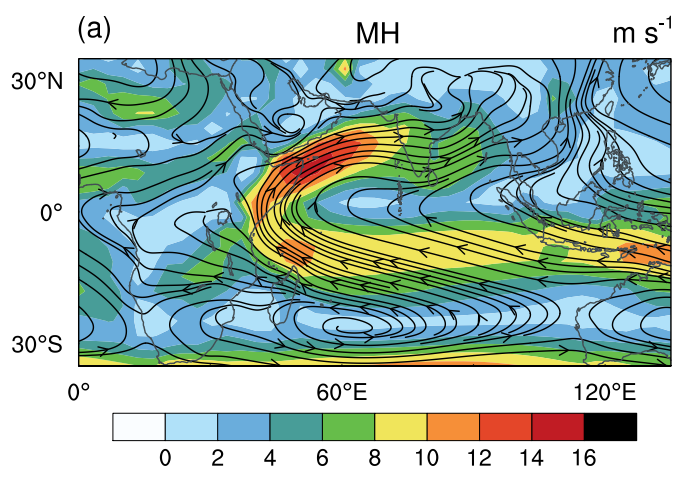

(b)

$\mathrm{Pl} \mathrm{m} \mathrm{s}^{-1}$
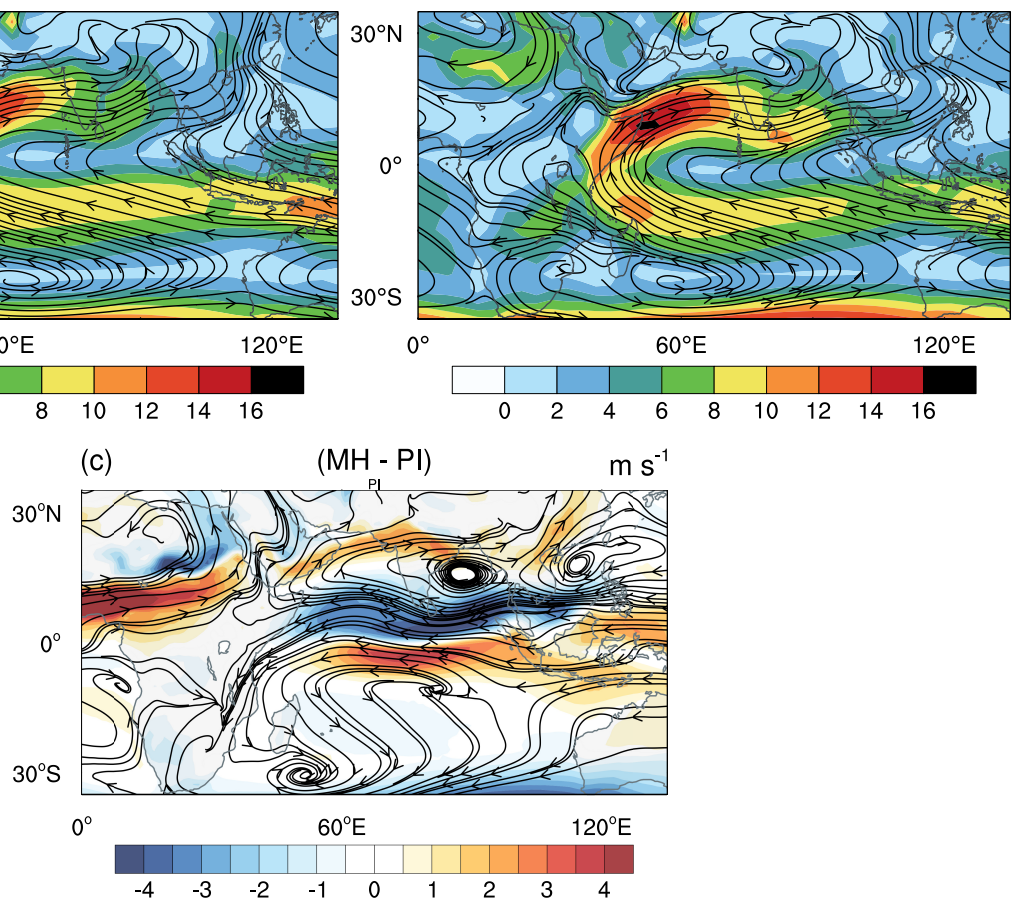

Figure S7. The JAS mean wind speed ( $850 \mathrm{hPa}$ ) in shading for (a) $\mathrm{MH}$, (b) PI, with streamlines of wind superimposed. The difference of the winds between $\mathrm{MH}$ and PI is shown in (c). there are two cyclonic circulations centered around $20^{\circ} \mathrm{E}$ longitude in both the northern and southern hemisphere (c). Also, there is a region of convergence at the equator. This is similar to the response of the atmosphere when subjected to total column heating at the equator. In this case, the increased convection over the western equatorial Indian Ocean provides the latent heat required to drive this atmospheric response.

\section{S2 Obliquity}

Here we show that the analysis used to explain precipitation response to precession can also be used to understand the response of precipitation to obliquity. Obliquity of Earth has a much weaker signal in comparison to precession (Fig. S8). Using ECEarth the maximum and minimum obliquity were simulated, while keeping eccentricity fixed at zero (circular orbit) (Bosmans

5 et al., 2015a, b). The land-sea shift in precipitation is still observed, albeit much weaker (Fig. S9). The factors leading to these changes are different than that for precession (Fig. S11). 


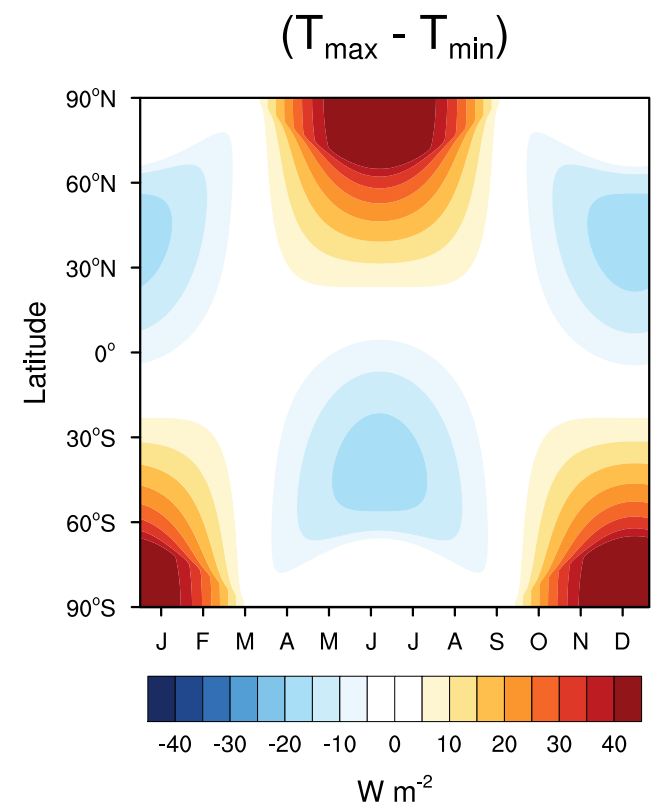

Figure S8. The insolation difference between the maximum and minimum tilt experiments $\left(\mathrm{T}_{\max }\right.$ and $\mathrm{T}_{\min }$ respectively). The change in insolation is very small over the tropics.

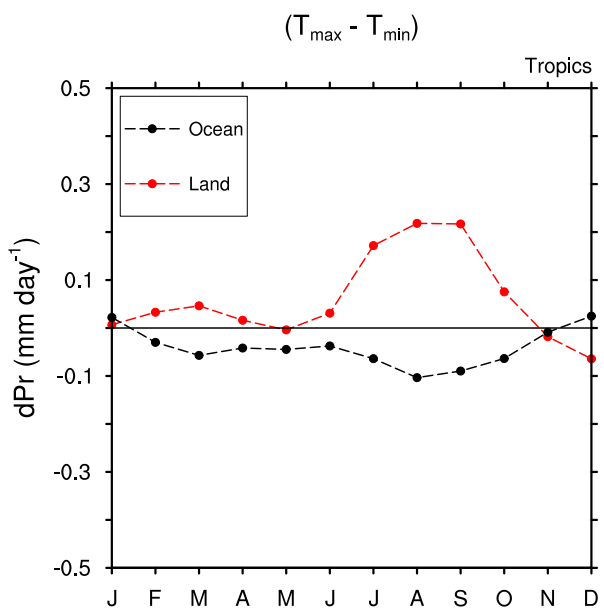

Figure S9. The difference in precipitation $\mathrm{T}_{\max }$ and $\mathrm{T}_{\min }$ for tropical land and ocean taken separately $\left(30^{\circ} \mathrm{S}-30^{\circ} \mathrm{N}\right)$. This shows the asymmetric response of the land and oceans to obliquity forcing. The changes in precipitation are very small compared to that for the precession and $\mathrm{MH}$ experiments. 
JJA
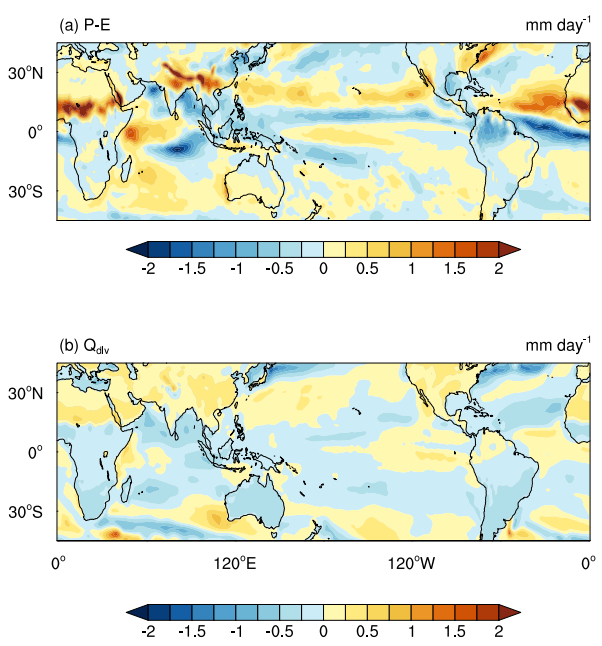

DJF
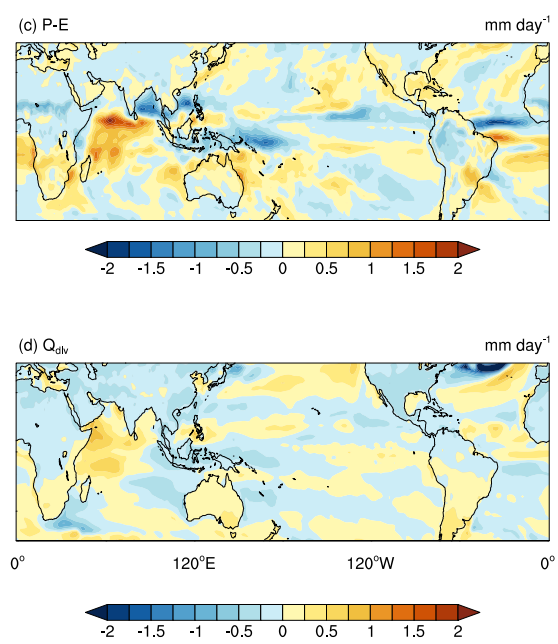

Figure S10. The difference in P-E (top panel (a) and (c)) and $\mathrm{Q}_{\text {div }}$ (bottom panel (b) and (d)). The left panel is for JJA mean and the right panel for DJF mean. This shows qualitatively that $\mathrm{Q}_{\text {div }}$ explains most of the changes in precipitation over the tropics.
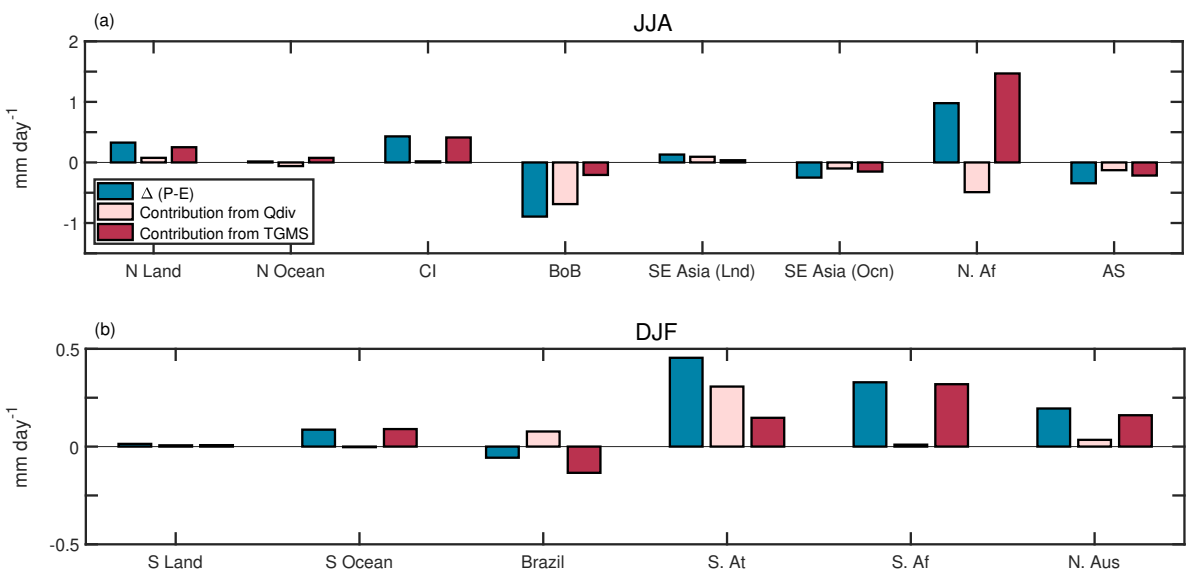

Figure S11. The contribution of $\mathrm{Q}_{\text {div }}$ and TGMS to the changes in P-E. The top panel (a) is for JJA mean and regions in the Northern Hemisphere, and the bottom panel (b) is for regions in the Southern Hemisphere and averaged over DJF. The blue stick is the change in P-E, while pink and red sticks represent the contribution from $\mathrm{Q}_{\text {div }}$ and TGMS. The abbreviations used in (a), N Land: Northern tropics (land only), N Ocean: Northern tropics (Ocean only), CI: Central India, BoB: Bay of Bengal, SE Asia (Lnd): South East Asia (land only), SE Asia (Ocn): South East Asia (Ocean only), N. Af: North Africa and AS: Arabian sea. And in (b), S Land: Southern tropics (land only), S Ocean: Southern tropics (ocean only), S. At: South Atlantic, S. Af: South Africa, N. Aus: North Australia. The coordinates of these regions are provided in table 2. This figure reveals that the changes in P-E between $\left(\mathrm{T}_{\min }-\mathrm{T}_{\max }\right)$ are due to different reasons than that in the precession or $\mathrm{MH}$ experiments.

\section{References}

Bosmans et al.: Monsoonal response to mid-holocene orbital forcing in a high resolution GCM, Climate of the Past, 8, 723, 2012.

Bosmans, J., Drijfhout, S., Tuenter, E., Hilgen, F., and Lourens, L.: Response of the North African summer monsoon to precession and obliquity forcings in the EC-Earth GCM, Climate dynamics, 44, 279-297, 2015a. 
Bosmans, J. H. C., Hilgen, F. J., Tuenter, E., and Lourens, L. J.: Obliquity forcing of low-latitude climate, Climate of the Past, 11, 1335-1346, https://doi.org/10.5194/cp-11-1335-2015, https://www.clim-past.net/11/1335/2015/, 2015b. 